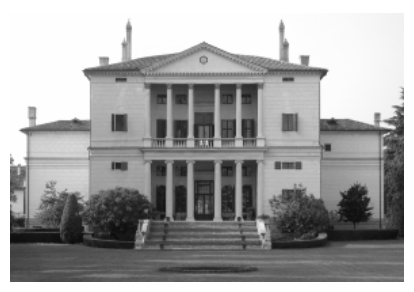

Keywords: Renaissance architecture, Palladio, surveying techniques, proportional analysis,

\section{Book Review}

Branko Mitrović and Stephen R. Wassell (eds.)

\section{Andrea Palladio: The Villa Cornaro in Piombino Dese}

New York: Acanthus Press, 2007.

Reviewed by Kim Williams

Via Cavour, 8

10123 Turin (Torino) ITALY

kwb@kimwilliamsbooks.com

I cannot claim to be the most objective reviewer of Andrea Palladio: The Villa Cornaro in Piombino Dese, edited by Branko Mitrović and Stephen R. Wassell, with contributions by Tim Ross and Melanie Bourke. I have known both of the editors for a good while and have spoken to them at length about the Villa Cornaro and Andrea Palladio, and even participated (in a very minor way, and principally by bringing along someone who did the dirty work) in the survey campaign. Some of my most pleasant hours have been spent with Sally and Carl Gable in "their" villa in Piombino Dese. On the other hand, what I lack in objectivity, the book amply makes up for in objectivity of its own, just one of the many respects in which this is not just another book about Palladio.

While most books set forth a theory, and use data to support it (in the case of architecture, measurements), this particular book on the Villa Cornaro does, of course, set forth theories, but these are not supported by selected data, but rather what is furnished is an abundance of data. One very great contribution that this book will make to Palladio scholarship is in providing a body of information that future Palladio scholars can turn to in elaborating and verifying their own theories, without being forced to agree with those set forth by Mitrović and Wassell. This is objectivity indeed, and more, generosity.

\title{
The essays
}

Mitrović's essay, "Designing the Villa Cornaro", begins with an overview of the current status of scholarship on Palladio's design theory, and then proceeds to contrast Mitrović's own theory with previous ones. Mitrović explains his principle of the "condition of concordance of heights", which he calls the $\mathrm{CCH}$ rule, through which the interrelatedness of Palladio's volumes is made clear. The information gleaned from the survey of the Villa Cornaro has allowed him to construct an in-depth proof of a hypothesis regarding Palladio's design process applied to a specific example that he had presented with broader strokes in his earlier publication, Learning from Palladio (W.W. Norton, 2004). His essay also provides the context for the detailed analysis of the projections of the attic base in the essay that follows.

When at the beginning of his chapter "The Piombino Dese Piede", Wassell writes, "I can state that the basic unit of measurement used in the construction of the Villa Cornaro 
... is equivalent to $38.4 \mathrm{~cm} .$. ” there is justly the ring of triumph. This is a simple datum, obtained after much hard work, a gold nugget found after sifting through lots of sand and grit. The guidelines for treating the data, including the philosophy regarding the treatment of the possible kinds of error, are explained in detail in the Introduction by Mitrović and Wassell.

Consider, for example, Wassell's particular study of the column bases on pp. 47-49. In order to see if what Palladio indicates in the Quattro libri for the projections of the attic base elements is put into practice in the Villa Cornaro, Wassell analyzes Palladio's illustration to produce the rules, next converts the rules to a measurable standard in terms of his survey, and then completes his investigation. In an appendix he supplies fourteen tables with a total of 448 raw measurements and 90 means and medians (this is data crunching). This is a massive bit of work to examine a minute architecture detail. It is justified because Palladio himself laid out such detailed proportions in his treatise: this is exactly how to see if Palladio followed his own specifications. For although a large part of the appeal and popularity of Palladio's work can be attributed to its accessibility and the visual clarity of his forms, underlying these are Palladio's formidable theories about how the individual elements relate to each other. So it should come as no surprise that the means for verifying them are formidable as well. In essence, the line drawings in the plates at the end of this book are deceptively simple, in the same way that Palladio's architecture is. Both drawings and architecture are clean and clear; both are based on an enormous quantity of information.

Other specific elements are described in the final two essays. Tim Ross compares the principal doors of the Villa Cornaro with the proportions set forth in the Quattro libri. I thought that the most interesting part of this discussion concerned "contractions", that is, the narrowing of the width of the door at its top, a concept similar to the entasis of a column. The essay by Melanie Bourke examines the two identical internal staircases that flank the back porch of the villa. Although these stairs are tucked away, and not as Palladio recommended, "still ... obvious and easy to find", and although they are in plain brick and otherwise unadorned, they are particularly pleasant to use

\section{The survey}

Another contribution that this book will make is that it will set a standard for future survey projects and their presentation. Clarity has always been a hallmark of Mitrovićs scholarly work: he not only tells you what his theory is, but he also explains his reasons for taking a particular approach towards the question. This same clarity is apparent in the Appendix, where Wassell, Bourke and Ross explain how the survey project was approached and the methodologies used.

My own broad experience with surveying and measuring has taught me that there are two equally arduous parts of the survey campaign: gathering the raw measurements and "crunching the data", that is, turning those raw measurements into a form that is meaningful, useful and accessible. Too much data can be as meaningless as too little.

Another reason that this is an unusual book is that it is rather a hybrid. One sense in which it is hybrid is that it is a collaboration between an architecture historian (Mitrović) and a mathematician (Wassell), although this distinction grossly oversimplifies the domains of knowledge of each, and I apologize to the authors in advance. In another sense, it is a combination of sixteenth-century architectural theory and twenty-first-century technology. 
The book's large $30 \times 42,5 \mathrm{~cm}$ format was necessary in order to accommodate the plates that report the results of the survey. (Not all publishers, myself included, are capable of producing this kind of book, and Barry Cenower of Acanthus Press is certainly to be commended.) But given the nature of the data presented, and the fact that the data was largely produced with the aid of a computer, one marvels that it is a book at all - the data almost cries out for a digital support. For instance, figs. 51 and 52 on p. 68 show the point cloud and the wireframe model of the Villa Cornaro, two very recent conceptual constructions. (Given the book's large format, it is too bad that these two figures were not represented at a larger scale.) These make it clear, however, that the original data produced was a set of Cartesian coordinates related to some origin $(0,0,0)$ from which the linear dimensions were produced. From the original set of coordinates, countless other dimensions could be had; it might even be possible to do much more modern kind of analysis, such as box-counting to determine fractal dimension. On the other hand, of course it is a book, because it is Palladio, for whom print was arguably as much of a medium for propagations of his ideas as his buildings were, and of course the coordinates are not given, for the linear dimensions are the only ones that Palladio himself would have worked with.

Naturally, a survey campaign of this scope makes perfect sense for an analysis of Palladio. Would it make as much sense, or provide, in the final analysis, the same quantity of useful information for a much later architect such as Louis Kahn? Although Kahn left no written texts on his preferred proportions or a system of proportions, he did leave traces in his buildings that have been sought out and convincingly presented. The question isn't even remotely relevant for a contemporary architect such as Gehry, who does not take formal proportions into consideration, and so for whose architecture accurate measurements add little or nothing to what one knows about the building.

What I perceived in this book is not so much the desire to undertake an arcane exercise in architectural history as a pressing need to set down what has been learned for posterity so we won't forget. Throughout the centuries interest in proportion has waxed and waned; in some epochs it is of the essence, while in others it is completely neglected. We live in an age when proportion does not much matter. But someday it will again. And when that time comes, the effort that Mitrović and Wassell have put into this survey will bear fruit. The metaphor of architecture as frozen music may be a bit worn, but it is still valid. Palladio knew how to make his proportions sing. When the time is right, this book will help assure that future architects can learn that music once again.

Mitrović and Wassell point out that the survey was done in ten days by four people and add "there is little reason to believe that similar surveys of Palladio's other work could not be done with similarly modest resources" (p. 16). They've neglected to mentions years - if not decades - of careful consideration they have given to Palladio's methods and results. Not all surveyors are so well-prepared, and the final result certainly benefits from this experience.

\section{About the reviewer}

Kim Williams is the Editor-in-Chief of the Nexus Network Journal. 
